\title{
Evaluation of resilient behavior of a clayey soil with polyethylene terephthalate (PET) insertion for application in pavements base
}

\author{
Bárbara Carvalho ${ }^{1, *}$, Michéle Casagrande ${ }^{2}$, and Márcio Farias ${ }^{2}$ \\ ${ }^{1}$ Pontifícia Universidade Católica do Rio de Janeiro, 22451-900, Rio de Janeiro, Brasil \\ ${ }^{2}$ Universidade de Brasília, 70910-900, Brasília, Brasil
}

\begin{abstract}
The growing production and consumption of PET bottles represent a major environmental problem because they end up being improperly discarded in nature or simply stocked. With the aim to attenuate the environmental problem caused by this residue, this research proposes the use of PET flakes as an alternative material for pavements base. In order to analyze the geotechnical performance of the material, physical tests, compaction and Cyclic Triaxial tests (Resilient Modulus) were carried out on pure soil as well as on the mixture of soil and PET flakes in weight percentages of 3, 5 and $7 \%$. The computer program SisPav (Franco, 2007) was used to perform a mechanistic-empirical design for a typical pavement structure with parameters obtained for the mixtures. The results indicated that the insertion of PET influences the mechanical behavior of the soil. It was found that resilient modulus increases, with respect to that of pure soil, for mixtures with the lowest content of PET (3\%). For tests with higher contents of PET flakes, the Resilient Modulus decreases. This research concluded that the clayey soil mixed with PET flakes can be used as an alternative material for pavements base, as long as a low content of flakes is used.
\end{abstract}

\section{Introduction}

The use of waste from various industrial activities in engineering works is an environmental solution that has become widely spread in recent years, especially because of the diffusion of the sustainable development concept. Following this trend, recent geotechnical research of pavements is testing the use of certain waste materials as an alternative for the construction of this type of structures.

The need to provide an appropriate destination for waste composed of PET bottles, which has been increasing due to the large production and consumption in the last years, has motivated this research. The author proposes the addition of PET flakes in a clayey soil from Distrito Federal/Brazil, to be used as an alternative material in pavements base.

There are many studies that evaluate the use of PET residue as an alternative material for pavements, all of them add PET in the asphalt mixture, as an aggregate or asphalt modifier. In Brazil, for example, Arao [1] and Queiroz [2] evaluated the behavior of asphalt mixtures with addition of PET flakes. The results of the measured parameters of the asphalt mixtures indicated a mechanical improvement of the material. Others researchers around the world, like Alzate [3], Moghaddam and Karin [4], and Hassan et al. [5] have also proved the feasibility of using recycled PET in different types of asphalt mixtures.

PET flakes was used by Louzada [6] in an experimental study of reinforced soil. She evaluated the mechanical behavior with static loading tests of mixtures of soil and PET (powder and flakes) with different contents. The results indicated an improved behavior for the desired purpose.

\subsection{Polyethylene Terephthalate (PET)}

The polyethylene terephthalate is a thermoplastic polymer, which means that this plastic material softens when warmed becoming a fluid that can be re-molded. The PET was developed in 1941, by John Rex Whinfield and James Tennant Dickson.

According to Romão et al. [7] PET became one of the more produced thermoplastic material in the world because of the mechanical properties, thermic properties, and the production cost.

Its large production and the long degradation time have made of PET a major problem for the environment. For this reason, it is extremely necessary the recycling of PET, in order to reduce the improper disposal in nature and the volume placed in the landfills. In Brazil, for example, $4 \%$ of the solid urban waste is composed of PET.

According to ABIPET [8], the PET recycling rate is $51 \%$ in Brazil. The most part of the recycled PET is used in textile industry, another part is destined to the production of alkyd resins and the rest is used in the manufacture of non-food packaging, plates, tapes, and tubes. Also, products made of recycled PET have a limited application, and cannot be used in beverage, food and pharmaceutical packaging due to contamination risk.

\footnotetext{
"Corresponding author: baviapiana@gmail.com
} 


\subsection{Resilient Modulus}

Medina and Motta [9] said that resilience means "energy stored in an elastically deformed body, which returns when the stresses causing the deformations cease". Thus, the resilience modulus represents the ratio of the applied stress and the corresponding resilient strain (Equation 1).

$$
M_{R}=\frac{\sigma_{d}}{\varepsilon_{r}}
$$

where $\mathrm{M}_{\mathrm{R}}$ is the esilient modulus (MPa), $\sigma_{\mathrm{d}}$ is the cyclic deviator stress $\left(\sigma_{1}-\sigma_{3}\right)(\mathrm{MPa})$, and $\varepsilon_{\mathrm{r}}$ is the resilient strain (vertical).

The resilient modulus can be determined through cyclic triaxial tests, in which different deviator stresses are applied to the specimen, at a constant frequency, combined with different confining stresses. The stresses applied repeatedly are to represent the effect of traffic on the pavement structure approaching the in-situ solicitations.

For each material tested the resilient modulus can be expressed by a mathematical model that is function of the state of stresses to which the specimen was subjected. For sandy soils the resilient modulus depends on the confining stress, while for clayey soils it depends on the deviator stress [9].

Other type of models relate the resilient modulus to deviator and confining stresses simultaneously. Two examples of this type of models are the composite model (Equation 2) developed by Macêdo (1996) [10] and the MEPDG model (Equation 3) developed by Witczak and Uzan (1988) [11]. These models have been widely used in recent years because its better fit for materials.

$$
\begin{gathered}
M_{R}=k_{1} \sigma_{3}^{k_{2}} \sigma_{d}^{k_{3}} \\
M_{R}=k_{1} p_{a}\left[\frac{\theta}{p_{a}}\right]^{k_{2}}\left[\frac{\tau_{o c t}}{p_{a}}+1\right]^{k_{3}}
\end{gathered}
$$

where $k_{1}, k_{2}$ and $k_{3}$ are regression coefficients, $p_{a}$ is the atmospheric pressure, $\theta$ is the first invariant of stress (calculated by Equation 4 ), and $\tau_{\text {oct }}$ is the octahedral shear stress (calculated by Equation 5).

$$
\begin{gathered}
\theta=\sigma_{1}+\sigma_{2}+\sigma_{3} \\
\tau_{\text {oct }}=\frac{1}{3} \sqrt{\left(\sigma_{1}-\sigma_{2}\right)^{2}+\left(\sigma_{1}-\sigma_{3}\right)^{2}+\left(\sigma_{2}-\sigma_{3}\right)^{2}}
\end{gathered}
$$

\section{Materials}

\subsection{Soil}

This study used a clayey soil classified as laterite, typically found over large regions of Brazil (Figure 1). In this case it was collected from the Experimental Field of the Postgraduate Geotechnical program of the University of Brasília, situated in Darcy Ribeiro Campus, Brasília.

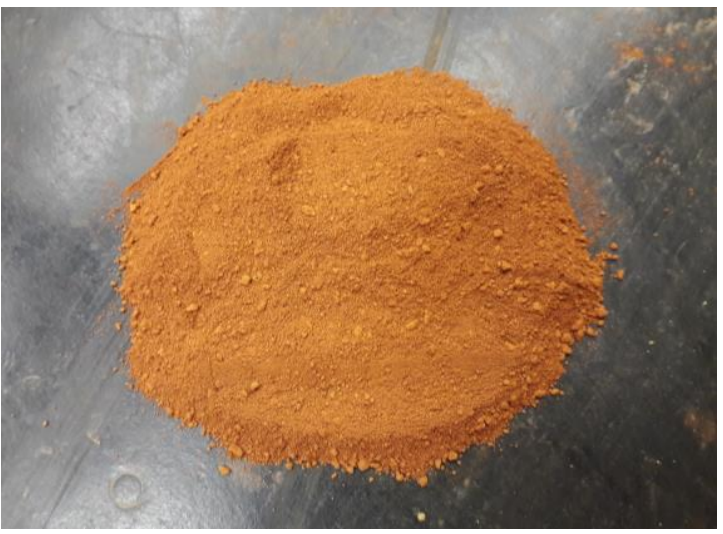

Fig. 1. Clayey soil from Experimental field of UnB.

\subsection{PET flakes}

PET flakes (Figure 2) used in this research is a result of PET bottle crushing, performed with the Radial LaFrance equipment (Figure 3), model SG-500F. This equipment belongs to the Laboratory of Structures and Materials of PUC-RIO.

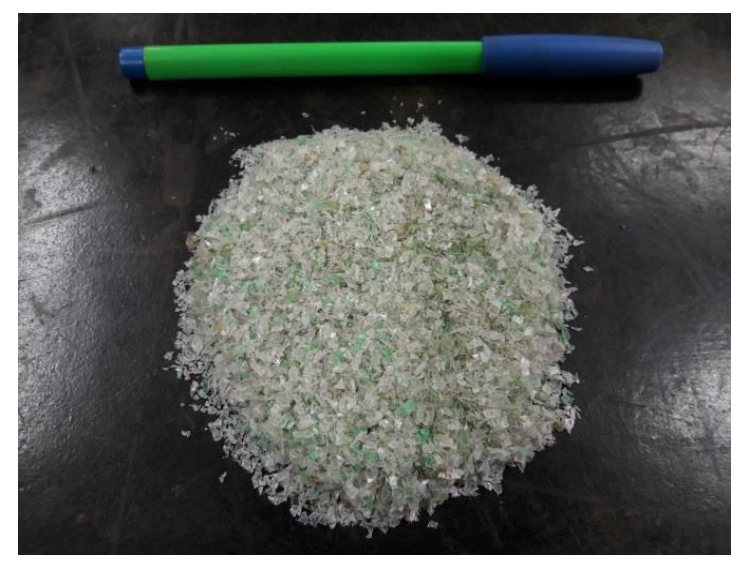

Fig. 2. PET flakes produced in PUC-Rio.

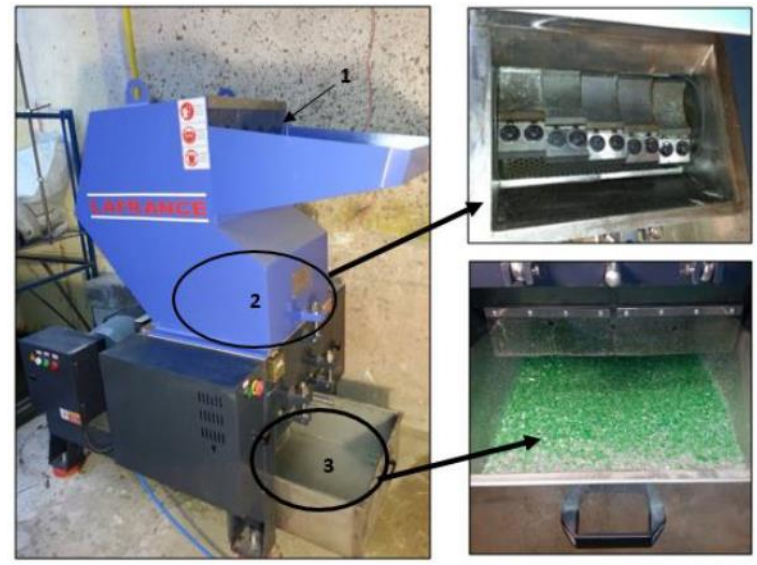

Fig. 3. Bottle crushing equipment. Source: Louzada [6]. 


\subsection{Mixtures}

The clayey soil was mixed with three different contents of PET flakes, 3, 5 and $7 \%$, on dry weight. The water was added according to the optimum moisture content, which was obtained from the compaction test, performed in each mixture. Table 1 summarizes the materials used and the abbreviations adopted for them.

Table 1. Abbreviations used for the soil and the mixtures.

\begin{tabular}{|c|c|c|c|}
\hline Material/Mixture & $\begin{array}{c}\text { Soil } \\
\mathbf{( \% )}\end{array}$ & $\begin{array}{c}\text { PET } \\
\text { flakes } \\
\mathbf{( \% )}\end{array}$ & Identification \\
\hline Pure Soil & 100 & 0 & SP \\
\hline Mixture 1 & 97 & 3 & S97F03 \\
\hline Mixture 2 & 95 & 5 & S95F05 \\
\hline Mixture 3 & 93 & 7 & S93F07 \\
\hline
\end{tabular}

\section{Experimental procedures}

With the aim to determine physical properties characterization tests were performed in the clayey soil. The tests were executed according to the Brazilian technical standard (Brazilian Association of Technical Standards - ABNT). Particle size analyses were executed according to Standard ABNT-NBR 7181/84. The liquid limit and plastic limit were obtained according to Standard ABNT-NBR 6459/84 and ABNT-NBR $7180 / 85$, respectively. The determination of the specific gravity of the soil was performed in the Penta pycnometer equipment. Particle size analyses and specific gravity tests were also performed for PET flakes.

The classification of the soil was made according to the Brazilian standard DNER-CLA 259/96 of the National Department of Highways and Roads (DNER), which is based on the methodology MCT (Miniature, Compacted, Tropical) developed by Nogami and Villibor (1981) [12]. This was necessary because there is an incoherence related to the behavior of tropical soils when these are classified by the traditional methodologies. The MCT classification depends on the parameters $c^{\prime}, d^{\prime}$ e $e^{\prime}$ obtained from two tests, the compaction test in the miniature equipment DNER-ME 258/94, and the test of loss of mass by immersion DNER-ME 256/94.

Compaction tests were carried out in the soil and the mixtures according to the Standard DNER-ME 228/84, using the intermediate energy $\left(847.8 \mathrm{kN}-\mathrm{m} / \mathrm{m}^{3}\right)$. This test consists in compacting a cylindrical specimen with diameter of $5 \mathrm{~cm}$ and height of $10 \mathrm{~cm}$, applying 6 blows on each side of the sample, using a hammer with $4.54 \mathrm{~kg}$ mass with a drop height of $30.5 \mathrm{~cm}$.

The resilient modulus was measured according to the American standard AASHTO T 307-99, applying principal stress pairs for base materials and sub-base of pavements. These tests were performed in the cyclic triaxial equipment, which belongs to INFRALAB laboratory at the Federal University of Brasília (Figure 4).

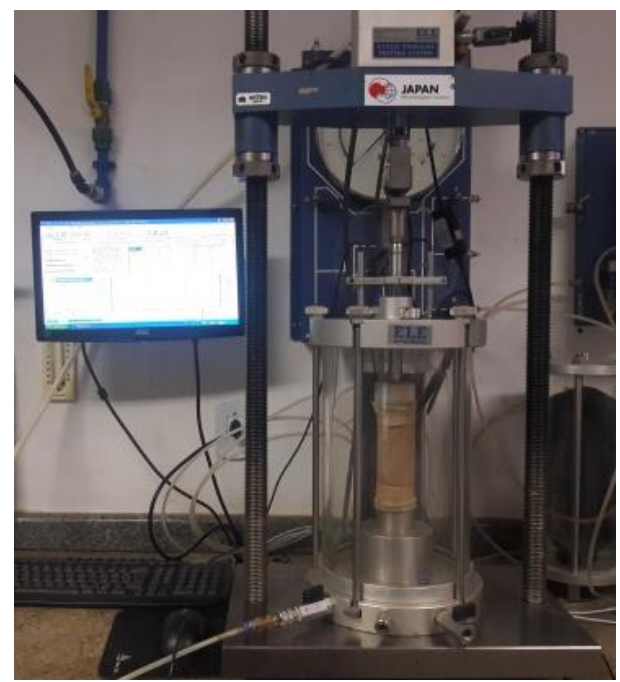

Fig. 4. Cyclic triaxial equipment from ELE brand International Limited England.

The results of physical and mechanical characterization tests of the materials were used as input on the computer program SisPav to perform a mechanistic-empirical design for a typical pavement structure.

\section{Results and analyses}

The characterization tests show that the soil is composed of $47.4 \%$ of clay, $30.5 \%$ of sand and $22.1 \%$ of silt. The particle size distribution is presented in Figure 5. The specific gravity of the soil, obtained in the Penta Pycnometer, was $2.7 \mathrm{~g} / \mathrm{cm}^{3}$. The liquid limit found was 42 $\%$ and the plastic limit was $27 \%$, which results in a Plastic Index of 15.

These results would classify the soil, according to the AASHTO classification, as a clayey material of the A-76 group. Based on this classification, the soil would have a poor performance for application in pavements, which turns to not be the case.

In the other hand, according to the MCT methodology the soil is classified as lateritic-clayey soil (LG'). These soils have high support capacity, low expansion, medium to high contraction and low permeability, making possible to use this soil as subgrade, reinforcement of subgrade or base of pavements.

The compaction test on the clayey soil indicated a maximum dry unit weight of $16.8 \mathrm{kN} / \mathrm{m}^{3}$ and optimum moisture of $19.8 \%$.

The maximum particle size of flakes used in this study is $2 \mathrm{~mm}$. The particle size distribution of PET flakes is also presented in Figure 5. The specific gravity, obtained in the Penta Pycnometer, was $1.39 \mathrm{~g} / \mathrm{cm}^{3}$. 


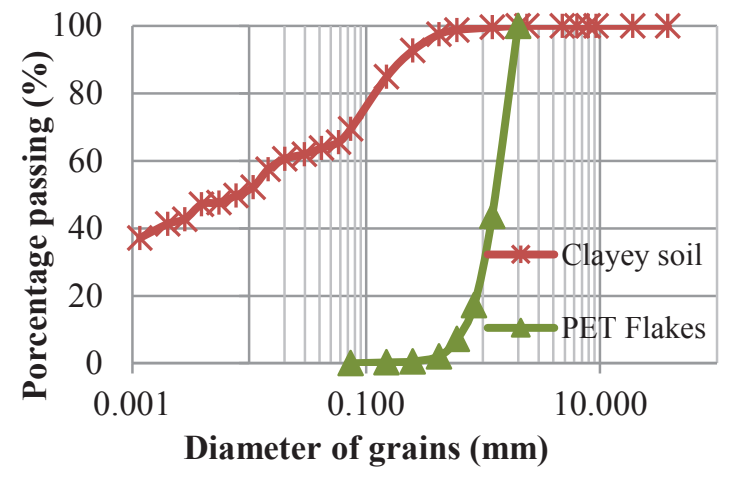

Fig. 5. Particle size distribution.

The variation of specific gravity of the mixtures as a function of PET flakes content is showed in Figure 6. The specific gravity of the mixture decreases as the amount of PET flakes added increases.

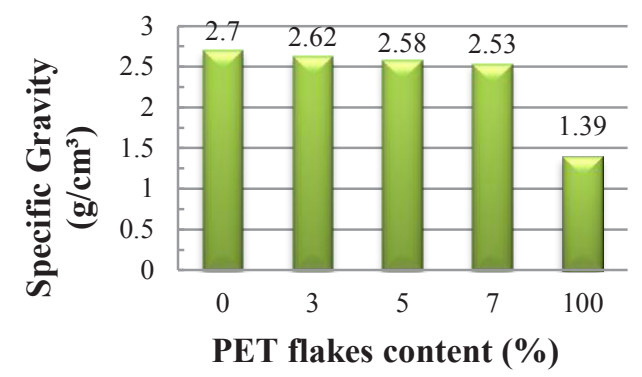

Fig. 6. Gs variation with PET flakes content.

The results of the compaction tests of the soil mixtures (Figure 7) show that the maximum dry unit weight of the mixture is lower than the maximum dry unit weight of the pure clayey soil, and it decreases as the amount of PET flake increases. However, the optimum moisture content for all the materials remains practically the same. Table 2 summarizes the results found in the compaction tests.

Table 2. Compaction tests results.

\begin{tabular}{|c|c|c|}
\hline Material ID & $\mathbf{W}_{\text {ot }}(\mathbf{\%})$ & $\gamma_{\mathrm{dmax}}\left(\mathbf{k N} / \mathbf{m}^{\mathbf{3}}\right)$ \\
\hline SP & 19.80 & 16.80 \\
\hline S97F03 & 20.00 & 16.50 \\
\hline S95F05 & 20.25 & 16.30 \\
\hline S93F07 & 19.25 & 16.00 \\
\hline
\end{tabular}

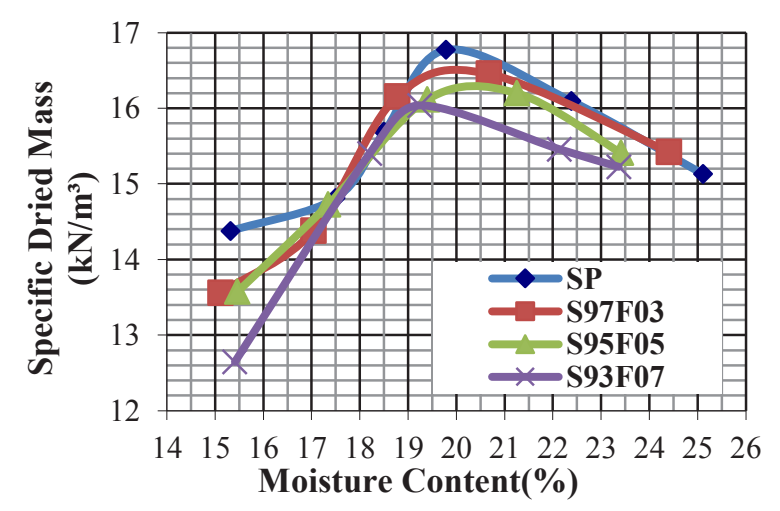

Fig. 7. Compaction test curves.
The resilient modulus test was performed on samples molded with the optimum moisture content and the maximum dried unit weight of each mixture. The range of values of resilient modulus found for each material, are presented in Table 3.

Table 3. Range of $M_{R}$ values for each material.

\begin{tabular}{|c|c|}
\hline $\begin{array}{c}\text { Material/ } \\
\text { Mixture }\end{array}$ & $\mathbf{M}_{\mathbf{R}} \mathbf{( M P a )}$ \\
\hline SP & $67-168$ \\
\hline S97F03 & $80-183$ \\
\hline S95F05 & $51-99$ \\
\hline S93F07 & $13-59$ \\
\hline
\end{tabular}

The tendency observed is that as PET content increases, the resilient modulus decreases. However, the mixture S97F03 shows higher values of $\mathrm{M}_{\mathrm{R}}$ than pure soil, which means that a content of $3 \%$ of PET flakes provides a mechanical stabilization and a strong adherence between the soil grains and the PET particles. The mixtures $\mathrm{S} 95 \mathrm{~F} 05$ and $\mathrm{S} 93 \mathrm{~F} 07$ have a range of $\mathrm{M}_{\mathrm{R}}$ values in average $35 \%$ and $70 \%$ lower than pure soil respectively. This results indicate that there is a threshold content of PET flake between 3 and 5\% for which the contact between PET particles increases to a point that reduces the stiffness of the mixture.

The resilient modulus analyses show that the pure soil and the mixtures can adjust to the composite model (Equation 2) and to the MEPDG model (Equation 3). These models are dependent on the confining stress and deviator stress. The regression coefficients for each model are shown in Table 4 and 5, with the corresponding correlation coefficient $\left(\mathrm{R}^{2}\right)$.

Table 4. Regression coefficients to the Composite Model.

\begin{tabular}{|c|c|c|c|c|}
\hline $\begin{array}{c}\text { Material/ } \\
\text { Mixture }\end{array}$ & $\mathbf{K}_{\mathbf{1}}$ & $\mathbf{K}_{\mathbf{2}}$ & $\mathbf{K}_{\mathbf{3}}$ & $\mathbf{R}^{\mathbf{2}}$ \\
\hline SP & 235.308 & 0.089 & 0.262 & 0.91 \\
\hline S97F03 & 235.887 & -0.105 & 0.411 & 0.90 \\
\hline S95F05 & 123.738 & 0.013 & 0.209 & 0.91 \\
\hline S93F07 & 75.604 & -0.206 & 0.626 & 0.89 \\
\hline
\end{tabular}

Table 5. Regression coefficients to the MEPDG Model.

\begin{tabular}{|c|c|c|c|c|}
\hline $\begin{array}{c}\text { Material/ } \\
\text { Mixture }\end{array}$ & $\mathbf{K}_{\mathbf{1}}$ & $\mathbf{K}_{\mathbf{2}}$ & $\mathbf{K}_{\mathbf{3}}$ & $\mathbf{R}^{\mathbf{2}}$ \\
\hline SP & 614.104 & 0.126 & 0.805 & 0.96 \\
\hline S97F03 & 736.235 & -0.807 & 1.372 & 0.92 \\
\hline S95F05 & 534.135 & 0.050 & 0.599 & 0.92 \\
\hline S93F07 & 155.355 & -0.151 & 2.001 & 0.85 \\
\hline
\end{tabular}

The Figures 8 to 11 present the fitted surfaces, in the $3 \mathrm{D}$ space $\left(\sigma_{3}, \sigma_{\mathrm{d}}, \mathrm{M}_{\mathrm{R}}\right)$, for the Composite Model. The purpose of these surfaces is to predict the Resilient Modulus for different combinations of confining stress and deviator stress.

All surfaces have a good fit to the experimental $M_{R}$ values obtained in the laboratory tests, representing better the dependence that this parameter have on both stresses. 


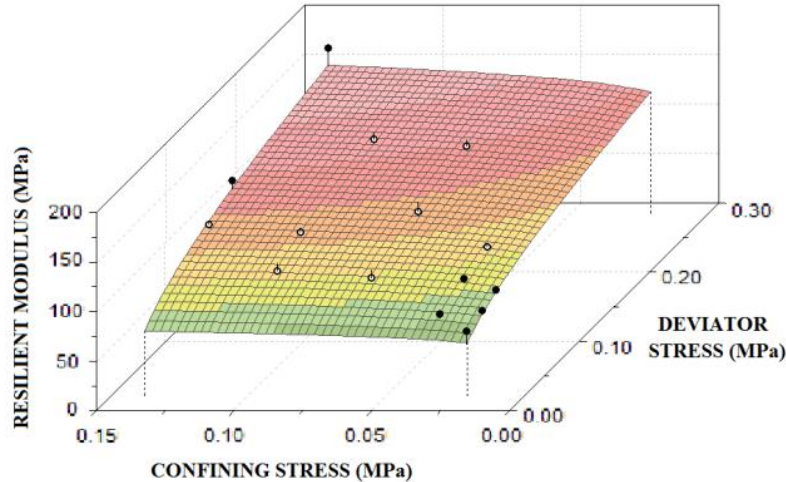

Fig. 8. Graphic 3D of the Pure Soil.

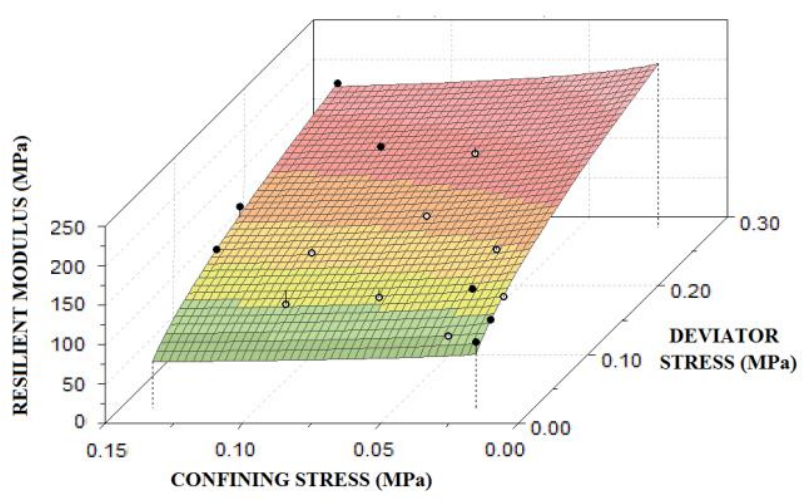

Fig. 9. Graphic 3D of the S97F03 mixture.

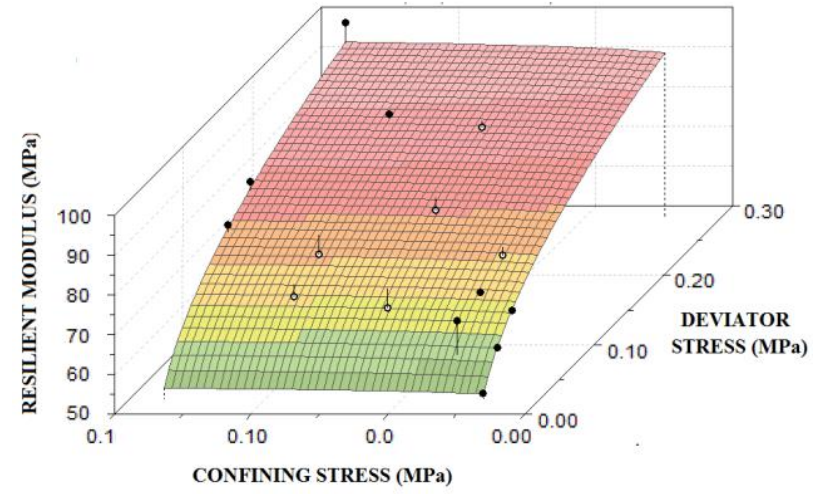

Fig. 10. Graphic 3D of the S95F05 mixture.

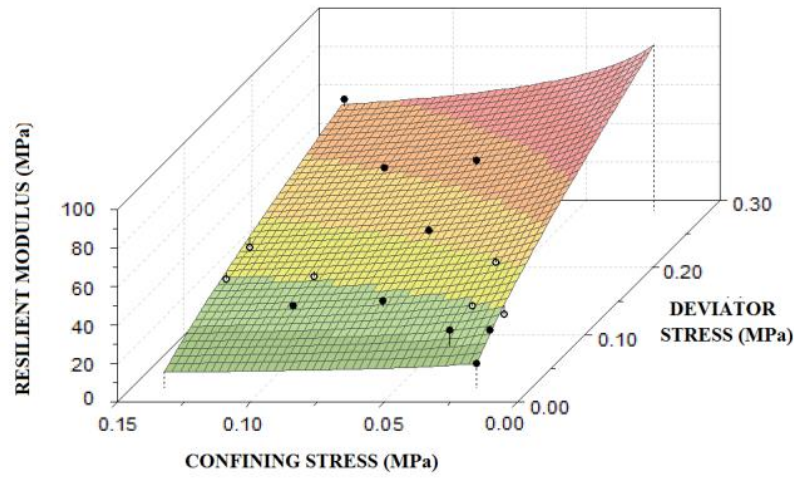

Fig. 11. Graphic 3D of the S93F07 mixture.

\subsection{Pavement design}

The pavement design was calculated using the computer program SisPav, developed by Franco [13]. Figure 12 shows a typically pavement structure which was considered in this design, where the mechanical properties of the asphalt and subgrade layers remain constant, varying only the thickness of the base according to the resilient parameters of each material tested.

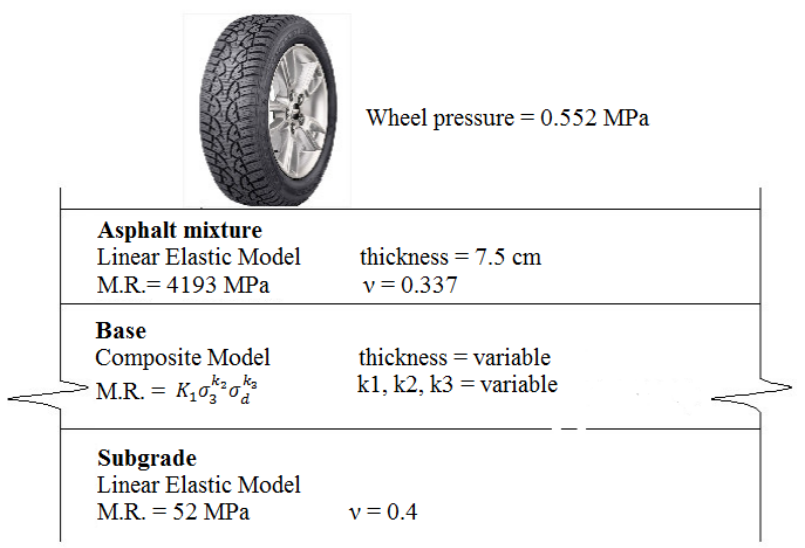

Fig. 12. Pavement structure adopted. Source: Vizcarra [14].

It was assumed a road located in Brasília, with traffic load consisting of 25000 repetitions of a $8,200 \mathrm{~kg}$ doubleaxis vehicle.

Figure 13 shows the thickness of the base for the designs computed by the program with each material.

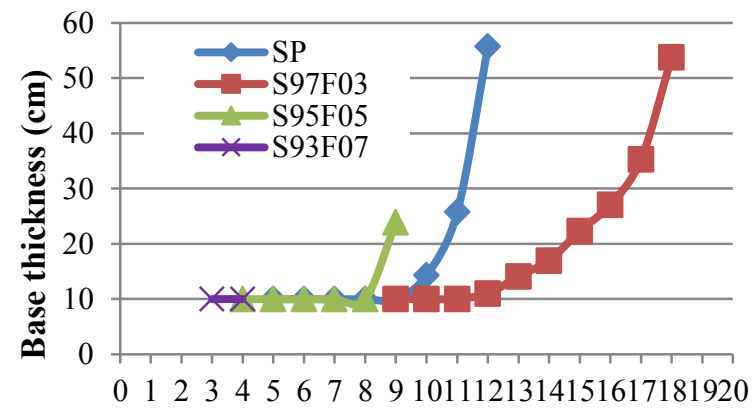

Project time (years)

Fig. 13. Layer Thickness according to project time.

The graphic shows that the size of the pavement with the mixture S97F03 results in a thinner base layer compared to that of pure soil, which is a consequence of the higher $\mathrm{M}_{\mathrm{R}}$ values. The layer thickness reduction can reach $80 \%$, for a project time of 12 years, which is the maximum project time for the pure soil. Also, the maximum project time reached by the S97F03 mixture is 18 years, that is 6 years more than that for pure soil.

As expected, the size of the pavement for the designs made considering the properties of mixtures S95F05 and S93F07 results in a thicker base layer and/or a shorter project time due to the lower $M_{R}$, that results in a lower estimated performance. However, the S95F05 mixture can still be used in a pavement designed for a project time less than 10 years, while S93F07 mixture is not 
recommended because of the very low mechanical properties that this material exhibits, resulting in a pavement with a maximum project time of 4 years.

\section{Conclusions}

The results of this research allow to conclude that the addition of PET flakes to a clayey soil modifies its properties. The addition of low contents of PET flakes (around 3\%) to the soil can be used as an alternative material for pavement bases.

The S97F03 mixture exhibited a considerable improvement on the mechanical behavior of the soil, increasing the resilient modulus. As a consequence, there is a reduction in the base layer thickness in the pavement design. For this study, the content of $3 \%$ of PET flakes showed the best results. It was also verified that the mixture with 5\% of PET flakes (S95F05) can be still used for pavements base for less project times.

It can be also concluded, from an environmental point of view, that the use of PET residue as an alternative material in pavements base, represents a good solution for its disposal and, consequently, for the mitigation of the great negative impact currently caused to the environment. Besides, the addition of PET to the soil results in a smaller volume of soil extracted from natural deposits, which also benefits the environment.

\section{References}

1. M. Arao, Masters Dissertation, DEC, PUC-RIO, 114 (2016)

2. B. Queiroz, Masters Dissertation, DEC, Universidade Federal da Paraíba, 125 (2016)

3. A. Alzate, Phd Thesis, Universidad Nacional de Colombia, 129 (2017)

4. T. B. Moghaddam, M. R. Karim, W. A. S. E. T. 6, 612-622 (2012)

5. A. Hassan, H. Ganjidoust, A. A. Maghanaki, J. W. M. R. 23, 4, 322-327 (2005)

6. N. Louzada, Master Dissertation, DEC, PUC-RIO, 126 (2015)

7. W. Romão, M. Spinacé, M.A. De Paoli, Polímeros: C. e Tec., 19, 121-132 (2009)

8. ABIPET (Associação Brasilieira da Indústria do PET). $9^{\circ}$ Censo Da Reciclagem de PET - Brasil. (2012)

9. J. Medina, G. Motta, Mecânica dos Pavimentos. 3rd ed. Editora UFRJ. Rio de Janeiro. Brasil. 570 (2015)

10. J. A. G. Macêdo, Phd Thesis, Universidade Federal do Rio de Janeiro (COPPE), (1996)

11. M. W. Witczak, J. Uzan, The Universal airport pavement design system, Report I of IV: Granular material characterization. University of Maryland, College Park (1988)
12. J. S. Nogami, D. F. Villibor, Uma nova classificação de solos para finalidades rodoviárias. Simpósio B. S. T. E, Rio de Janeiro, 30-41 (1981)

13. F.A. Franco, Phd Thesis, Universidade Federal do Rio de Janeiro (COPPE), 315 (2007)

14. G. O. Vizcarra, Master Dissertation, DEC, PUC-RIO, 120 (2010) 